\title{
O ATENDIMENTO DE UM ESTUDANTE COM TRANSTORNO DO ESPECTRO DO AUTISMO NO CENTRO DE PROMOÇÃO PARA INCLUSÃO DIGITAL, ESCOLAR E SOCIAL
}

\author{
Denner Dias Barros ${ }^{1}$, Janiele de Souza Santos ${ }^{1}$, Ana Virginia Isiano Lima ${ }^{2}$, Ana Mayra Samuel Silva ${ }^{2}$, \\ Danielle Aparecida do Nascimento Santos ${ }^{3}$, Elisa Tomoe Moriya Schlünzen ${ }^{4}$ \\ Universidade Estadual Paulista Júlio de Mesquita Filho - FCT/UNESP. ${ }^{1}$ Curso de Matemática, Presidente Prudente - SP. \\ ${ }^{2}$ Curso de Pedagogia, Presidente Prudente - SP. ${ }^{3}$ Mestre em Educação, Presidente Prudente - SP. ${ }^{4}$ Professora \\ assistente - autárquica, Presidente Prudente - SP. E-mail: dennerdias12@gmail.com - Órgão de fomento: CAPES
}

\section{RESUMO}

O Centro de Promoção para Inclusão Digital, Escolar e Social (CPIDES), desde 2010 oferece apoio aos Estudantes Público-Alvo da Educação Especial (EPAEE) e através do desenvolvimento de atividades pedagógicas mediadas por estagiários dos cursos de licenciatura da Faculdade de Ciências e Tecnologias - FCT/Unesp, buscam-se meios para promover a inclusão digital, escolar e social desses EPAEE. $O$ trabalho de intervenção pedagógica realizado junto a um estudantes com Transtorno do Espectro do Autismo (TEA) tem fundamentação no trabalho com projetos, onde desenvolve-se inicialmente o estabelecimento de uma rotina do mesmo a fim de proporcionar o afloramento de suas habilidades e ampliação de suas potencialidades. Neste trabalho serão descritas as situações de aprendizagem desenvolvidas no trabalho com um estudante com TEA e os resultados das intervenções.

Palavras-chave: Inclusão Escolar, Transtorno do Espectro do Autismo, Situações de Aprendizagem.

\section{EDUCATIONAL SERVICE IN CENTER OF PROMOTION FOR DIGITAL, EDUCATIONAL AND SOCIAL INCLUSION FOR A STUDENT WITH AUTISM SPECTRUM DISORDER}

\begin{abstract}
The Center of Promotion for Digital, Educational and Social Inclusion (CPIDES) since 2010 provides support for Students with Special Educational Needs as the Target Audience (EPAEE) and through educational activities mediated by trainees of degree courses of the Faculty of Sciences and Technology - FCT of State University of São Paulo "Julio de Mesquita Filho" - UNESP, seek to promote digital, educational and social inclusion of EPAEE attending in CPIDES. Working with students with Autism Spectrum Disorder (TEA), held at the center, has its peculiarities and project work and the creation of a routine are attitudes that aim to provide these students the outcropping of their skills and broaden their potential. This paper aims to describe the learning situations developed in working with a student with TEA in CPIDES.
\end{abstract}

Keywords: School Inclusion, Autism Spectrum Disorder, Specialized Educational Services. 


\section{INTRODUÇÃO E OBJETIVO}

O Transtorno do Espectro do Autismo ${ }^{1}$ (TEA) não é somente uma categoria única, mas é considerado um contínuo e contempla diferentes graus de classificação. Segundo Belisário Filho e Cunha (2010) o termo foi inicialmente descrito por Wing e Gould no ano de 1979, quando ao estudarem incidências na dificuldade de reciprocidade social em crianças identificaram sintomas semelhantes ao do autismo, mas que não poderiam levar à denominação de autistas propriamente ditos.

Com a lei no 12.764, de 27 de dezembro de 2012 foi instituída a Política Nacional de Proteção dos Direitos da Pessoa com Transtorno do Espectro Autista, que estabelece diretrizes para sua consecução, tendo como principais objetivos a exclusão total de qualquer forma de discriminação à pessoa com TEA, o diagnóstico apropriado, a estimulação precoce das crianças com TEA e a inserção dessas pessoas em todos os setores da sociedade. Nesse sentido, para esse público o Ministério da Educação (MEC) reafirma a oferta do Atendimento Educacional Especializado e ainda para os casos de necessidade comprovada, o direito ao acompanhamento por um profissional especializado na sala comum do ensino regular.

Até 2013 o trabalho com as pessoas com TEA era direcionado pelo Manual Diagnóstico e Estatístico de Transtornos Mentais (DSM-IV-TR). Esse manual trazia como terminologia o Transtorno Invasivo do Desenvolvimento (TID) englobando: "Transtorno Autista, Transtorno de Asperger, Transtorno de Rett, Transtorno Desintegrativo da Infância e Transtorno Invasivo do Desenvolvimento sem Outra Especificação". Também se utilizava a Classificação Internacional de Doenças (CID-10) que denomina como Transtorno Global do Desenvolvimento: "Autismo Infantil, Autismo Atípico, Síndrome de Rett, Transtorno Desintegrativo da Infância, Transtorno com Hipercinesia associada a Retardo Mental e Movimentos Esteriotipados, Síndrome de Asperger, Outros Transtornos Globais do Desenvolvimento e Transtornos Globais do Desenvolvimento e Transtornos Globais do Desenvolvimento Não Especificados".

Com a Publicação do Manual Diagnóstico e Estatístico de Transtornos Mentais (DSM - 5) em maio de 2013, o TEA foi considerado como categoria de diagnóstico. Segundo Khoury (2014, pg.11):

O DSM-5 agrupou e incluiu quatro das cinco categorias dos TID do DSM-IV na condição de Transtorno do Espectro Autismo (TEA). Foram elas: Transtorno Autista, Transtorno Desintegrativo da Infância, Transtorno de Asperger e Transtorno Invasivo do Desenvolvimento Sem Outra Especificação. De acordo com o DSM-5, esses transtornos não terão mais validade em termos de

\footnotetext{
${ }^{1}$ Também se encontra na legislação, manuais e bibliografia em geral, o termo "Transtorno do Espectro Autista" sob o mesmo significado. 
condições diagnósticas distintas. Assim, passarão a ser considerados no mesmo espectro do autismo.

Muitos especialistas na área do TEA criticaram essa nova classificação realizada pela "American Psychiatry Association" (APA). De acordo com Araújo (2014), apesar de inúmeras críticas frente à adoção dessa nova classificação, que argumentam que esses transtornos apresentam diferenças significativas, a APA justifica que não há vantagens diagnósticas ou terapêuticas nessa divisão e acrescenta que a dificuldade em criar subclassificações do TEA poderia confundir o clínico e dificultar e/ou atrasar um diagnóstico devidamente apropriado.

Em 2010 o Centro de Promoção para Inclusão Digital, Escolar e Social (CPIDES), da Universidade Estadual Paulista Júlio de Mesquita Filho (Unesp), campus de Presidente Prudente/SP passou a desenvolver pesquisas de cunho teórico e prático por meio dos membros do Grupo de Pesquisa Ambientes Potencializadores para a Inclusão, e de uma estrutura com salas pedagógicas, biblioteca, sala de informática e salas de desenvolvimento.

No CPIDES realizam-se atendimentos aos Estudantes Público-Alvo da Educação Especial $(E P A E E)^{2}$, através da utilização de recursos pedagógicos acessíveis e recursos de Tecnologia Assistiva na sala de informática e na Sala de Recursos Multifuncionais (SRM) - ambientes dotados de equipamentos pedagógicos e tecnológicos, mobiliários e materiais didáticos voltados para a oferta do AEE. Os atendimentos são realizados de maneira individual ou em grupo, semanalmente, uma ou duas horas por semana. As atividades são selecionadas e aplicadas de acordo com a característica do público-alvo, nível de escolarização e com os temas de interesse do mesmo.

Esses atendimentos buscam promover atividades que contemplem a abordagem metodológica Construcionista, Contextualizada e Significativa (CCS), que segundo Schlünzen (2000)

É um ambiente favorável que desperta o interesse do aluno e o motiva a explorar, a pesquisar, a descrever, a refletir, a depurar as suas ideias. [...] As informações que são significativas para o aluno podem ser transformadas em conhecimento [...] O aluno consegue descobrir a relação com tudo que está aprendendo, a partir de seus interesses individuais dentro do seu contexto.

Considerando essas premissas, o presente trabalho tem como elemento central o sujeito $\mathrm{R}^{3}$, de 5 anos de idade, ainda não frequenta o ensino básico regular, diagnosticado com TEA, que frequenta o CPIDES há cerca de 7 meses.

\footnotetext{
${ }^{2}$ Pessoas com deficiências físicas, intelectuais, sensoriais e múltiplas; transtorno do espectro autista e altas habilidades/superdotação.

${ }^{3}$ Fez-se uso da sigla R para preservar a identidade do estudante. 
O objetivo é analisar quais estratégias pedagógicas desenvolvidas junto ao estudante propiciam a criação de uma rotina para o seu atendimento na SRM do CPIDES em uma perspectiva inclusiva.

\section{MÉTODO}

O atendimento realizado com os estudantes possui aprovação do Comitê de Ética e Pesquisa (CEP) com o registro de processo 106/2009.

No início da pesquisa, que se classifica como qualitativa, do tipo intervenção, foi realizada, junto com os pais do estudante $R$, uma entrevista estruturada para levantamento de informações pertinentes à estruturação e andamento dos atendimentos, contendo dados referentes ao diagnóstico, características pessoais e familiares.

Em um segundo momento foi realizado um teste diagnóstico com $\mathrm{R}$ para constatar os objetivos de aprendizagem, potencialidades, dificuldades e interesses do estudante.

Antes de dar início aos atendimentos, foi realizado um levantamento bibliográfico sobre as principais características da pessoa com TEA, em artigos científicos e sites especializados no assunto. Em seguida, realizamos uma análise criteriosa da literatura selecionada. Diante das informações obtidas na entrevista e no teste diagnóstico e no levantamento bibliográfico, foi possível elaborar planos de aulas, contendo o planejamento prévio das atividades.

Inicialmente o estudante mostrou-se receoso quanto à realização das atividades, portanto fez-se necessária a elaboração de uma rotina de passos, para que o estudante pudesse compreender os momentos da realização do atendimento na SRM do CPIDES.

A rotina criada para o trabalho com o estudante $R$, contou com três momentos: Leitura e Escrita, Atividades com Materiais Concretos e Atividades usando Tecnologias.

As atividades de Leitura e Escrita foram consideradas importantes, pois o estudante está em processo de alfabetização. Para tanto, realizamos atividades baseadas em histórias de livros da SRM ou atividades retiradas da internet, sempre com temas de acordo com a preferência do estudante R.

A utilização de Materiais Concretos é o momento em que R., através da manipulação de materiais pedagógicos como: Jogos, Tangran, blocos de montar, brinquedos, entre outros, interagiu para que os conceitos trabalhados no primeiro momento com as atividades de leitura e escrita pudessem ser contextualizados e apresentados novamente.

Para as atividades usando Tecnologias, utilizamos como base os Objetos Educacionais (OE), como "Fazenda Rived" que trabalha questões como relações biunívocas, sequências lógicas e 
contagem, "Um Dia de Compras", "Viagem Espacial", que possui atividades de alfabetização. Esses e outros OA foram pesquisados e selecionados a partir do Banco Internacional de Objetos Educacionais (BIOE). Os recursos tecnológicos foram utilizados sempre aliados às atividades anteriores para que o atendimento tivesse uma sequência didática e todas as atividades estivessem relacionadas com as outras, tornando-se significativas.

\section{RESULTADOS}

Os avanços obtidos pelo estudante foram positivos, pois as atividades realizadas foram centradas nos seus interesses e necessidades, possibilitando uma aprendizagem significativa.

Com a realização das atividades mediadas pelos estagiários, o estudante R. mostrou-se mais familiarizado com o ambiente e mais disposto a realizar as atividades propostas. Mediante a utilização da rotina foi possível estabelecer parâmetros para que o estudante cumprisse cada atividade proposta no devido momento estabelecido para o transcorrer do atendimento. Os avanços nas interações sociais foram os mais relevantes. Com a interação estudante/estagiário foi possível criar um vínculo pedagógico essencial para o andamento de todas as atividades realizadas.

A utilização das Tecnologias proporcionou aos estudantes atividades motivadoras e atrativas. Através dos $\mathrm{OE}$, o estudante pode explorar alguns conceitos trabalhados anteriormente de maneira lúdica e contextualizada.

O processo de ensino obteve avanços significativos. Os mediadores (estagiários) tiveram um papel fundamental em despertar a curiosidade e interesse do estudante, possibilitando a realização de atividades contextualizadas e a construção do conhecimento básico de leitura e escrita, utilização da tecnologia e aprendizagem da matemática.

\section{DISCUSSÃO}

O trabalho com projetos e a criação da rotina foram essenciais durante todo o processo, uma vez que permitiram respeitar os diferentes temas abordados nos atendimentos, de diversas maneiras e utilizando de diversas estratégias.

"O professor que trabalha com projetos de aprendizagem respeita os diferentes estilos e ritmos de trabalho dos alunos desde a etapa de planejamento, escolha do tema e respectiva problemática a ser investigada. Não é o professor quem planeja para os alunos executarem, ambos são parceiros e sujeitos de aprendizagem, cada um atuando segundo o seu papel e nível de desenvolvimento" (ALMEIDA, 1999, p. 2). 
No decorrer do processo, analisamos o desenvolvimento do aluno $\mathrm{R}$ sempre de maneira criteriosa, através de situações lúdicas para permitir que o estudante se expressasse de maneira livre e para que a avaliação fosse contínua e prospectiva. Para Santos (2006, p. 83):

Uma vez que as informações sejam sistematizadas e o conhecimento esteja sendo elaborado de uma forma significativa, o professor poderá estabelecer critérios para avaliar os avanços obtidos, bem como, determinar também as barreiras que não foram quebradas e buscar soluções para saná-las, se necessário.

Portanto, ressaltamos que as situações de aprendizagem criadas em uma perspectiva inclusiva, aliada à criação da rotina foram essenciais para o desenvolvimento do estudante.

\section{CONCLUSÃO}

O trabalho realizado foi centrado nas potencialidades do estudante, buscando aflorar suas habilidades e sanar algumas de suas dificuldades. A mediação dos estagiários foi essencial para que fossem estimuladas as interações sociais no decorrer do trabalho com o estudante.

\section{REFERÊNCIAS}

ALMEIDA, M. E. Projeto: uma nova cultura de aprendizagem. São Paulo: PUC/SP, 1999. American Psychiatry Association. Diagnostic and Statistical Manual of Mental disorders - DSM-5. 5th.ed. Washington: American Psychiatry Association, 2013.

BIOE - Banco Internacional de Objetos Educacionais. Disponível em: < http://www.objetoseducacionais2.mec.gov.br/<. Acesso em: 05 ago. 2014.

BRASIL. Lei no 12.764, de 27 de dezembro de 2012. Institui a Política Nacional de Proteção dos Direitos da Pessoa com Transtorno do Espectro Autista; e altera o § 30 do art. 98 da Lei $n^{\circ} 8.112$, de 11 de dezembro de 1990. Diário Oficial da União, Brasília, DF, 27 dez. 2012. Disponível em: http://www.planalto.gov.br/ccivil_03/_ato2011-2014/2012/lei/l12764.htm. Acesso em: 05 ago. 2014.

DSM-IV-TR ${ }^{T M}$ - Manual Diagnóstico e Estatístico de Transtornos mentais, trad. Cláudia Dornelles; - 4.ed. rev. Porto Alegre: Artmed, 2002.

BELISÁRIO FILHO, J. F; CUNHA, P. A Educação Especial na Perspectiva da inclusão escolar: transtornos globais do desenvolvimento. Brasília: MEC/SEESP, 2010.

BRASIL: Ministério da Educação. Secretaria de Educação Especial. Política Nacional de Educação Especial na perspectiva da Educação Inclusiva. Brasília: MEC/SEESP, 2007.

KHOURY, L. P. et al. Manejo comportamental de crianças com Transtornos do Espectro do Autismo em condição de inclusão escolar: guia de orientação a professores [livro eletrônico]. -São Paulo : Memnon, 2014. 
SANTOS, D. A. N. A formação de professores de uma escola da rede pública estadual em serviço para o trabalho com projetos utilizando as tecnologias de informação e comunicação. 2006, 226f. Dissertação (Mestrado em Educação), Universidade Estadual Paulista "Júlio de Mesquita Filho", Presidente Prudente, 2006.

SCHLÜNZEN, E. T. M. Mudanças nas práticas pedagógicas do professor: criando um ambiente construcionista, contextualizado e significativo para crianças com necessidades especiais físicas. 2000, 240 f. Tese (Doutorado em Educação: Currículo), Pontifícia Universidade Católica de São Paulo, São Paulo, 2000. 